\title{
Mujeres responsables: Aportes para reflexionar acerca de la carga sexista del discurso jurídico de la responsabilidad
}

Responsible women: Contributions to reflect on the sexist burden of the legal discourse of responsibility

\author{
Juan Martín Almejún ${ }^{1}$ \\ Universidad Nacional de Mar del Plata - Argentina
}

Revista Derechos en Acción ISSN 2525-1678/ e-ISSN 2525-1686

Año 5/Nํo 16 Invierno 2020 (21 junio a 20 septiembre), 714-730

DOl: https://doi.org/10.24215/25251678e440

Recibido: 01/02/2020

Aprobado: 15/09/2020

\section{Introducción}

El propósito de este trabajo es examinar brevemente la relación entre el lenguaje de la responsabilidad y el lugar que el discurso jurídico le asigna a las mujeres. Se desarrollarán dos ideas: (1) la Teoría Crítica y la Teoría Feminista han puesto en evidencia que el derecho ha sido históricamente una disciplina machista; (2) esta afirmación se evidencia en el lenguaje judicial y doctrinario y en las categorizaciones de la responsabilidad que subyacen tanto en el derecho privado como en el derecho penal.

Con ese fin se procurará introducir sucintamente el desarrollo de la teoría del derecho como construcción ficcional vinculada a valores e ideales de masculinidad. Seguidamente se procurará introducir los aportes de los estudios críticos y la

\footnotetext{
1 Abogado. Ministerio de Justicia y Derechos Humanos, Universidad Nacional de Mar del Plata, Universidad de Palermo. (ORCID: https://orcid.org/0000-0002-8547-1295).
} 
crítica feminista para luego, analizar algunas citas doctrinarias y casos jurisprudenciales que refuerzan la idea central de este artículo.

Es evidente que el método exploratorio-descriptivo aquí utilizado presenta ciertas limitaciones a la hora de permitirnos elaborar una propuesta concreta de mejora a la realidad que aquí se esbozará. Sin embargo, el valor que se le intenta asignar a este trabajo versa en la intención de revisar los alcances teóricos de ciertas categorías tradicionales y la necesidad de desplazar sus sentidos.

\section{El derecho moderno y la crítica feminista}

Como punto de partida es dable recordar que desde sus orígenes el derecho moderno se pensó como herramienta para garantizar la integración normativa y la coerción de la ley en la resolución de los conflictos. El derecho privado moderno se estructuró mediante ciertos axiomas capitalistas: todo puede ser mercancía y toda mercancía ha de tener una voz para aceptar o rechazar el intercambio (Capella, 2008: 134). Esto es explicado desde la idea que todos los bienes tienden a asumir la forma de objetos de intercambio en algún mercado y así, mediante la voz de la mercancía se edificó el sujeto del derecho privado y sus derivados como la persona jurídica y el sujeto de derecho.

Surgieron para los ciudadanos derechos como la propiedad, la vida y el derecho a contratar, ahora asumido como natural. La norma, dentro de esta sociedad tendió a la regulación y la normalización y jugó y juega un papel fundamental, siendo el mecanismo que permite la interacción entre lo individual y lo colectivo. Se distinguió claramente la esfera pública de la privada, lo que generó que el individuo asumió dos fases de interacción bien separadas. En ese esquema, las mujeres fueron relegadas por los hombres a la esfera doméstica y de la familia, excluidas del mundo público y económico (Harari y Pastorino, 2000: 145). Por otro lado, se originaron las grandes codificaciones como formas lógicas y razonables de regular las situaciones jurídicas 
de las relaciones humanas. Comenzó a buscarse la previsibilidad y la estabilidad en el mercado, que traducido ello en el campo del derecho significó la búsqueda de la seguridad jurídica.

La ciencia y el derecho se fusionaron a través de una significativa relación de cooperación que es uno de los rasgos de la modernidad (De Sousa Santos, 2006:35). Ese intercambio permitió el pase de la ciencia al derecho y viceversa dentro de las instituciones. Así, por ejemplo, algunas disidencias sexuales han sido negadas por el derecho y condenadas por la ciencia y las mujeres han sido confinadas a un rol secundario por el derecho y catalogadas, en caso de oponerse a la norma, de "locas" desde los valores de la ciencia.

Se simplificó la existencia a dos opciones donde cabe todo tipo de vínculo y acción. De esta manera, por muchos años prevaleció un solo modelo de vida y una sola forma de concebir las relaciones. Se instauró también la frontera que divide las acciones de los hombres en función de lo que establece el Estado, reducido ello al binomio "legal" y "no legal". Esa construcción binomial, que atravesó todos los campos del conocimiento y de representación social, impactó eficazmente hasta nuestros días en la separación de lo "masculino" y lo "femenino". En ese sentido, Olsen (2009) afirma que en cada par de esa construcción "el término identificado como "masculino" es privilegiado como superior, mientras que el otro es considerado como negativo, corrupto o inferior" (p.481).

El derecho se identifica con lo masculino y por ello continúa la autora argumentando que:

"La división entre lo masculino y lo femenino ha sido crucial para este sistema dual de pensamiento. Los hombres se han identificado a sí mismos con un lado de los dualismos: con lo racional, lo activo, el pensamiento, la razón, la cultura, el poder, lo objetivo, lo abstracto, lo universal. Las mujeres resultaron proyectadas hacia el otro lado e identificadas con lo irracional, lo pasivo, el sentimiento, la emoción, la naturaleza, la sensibilidad, lo subjetivo, lo concreto, lo particular" (Osen, 2009: 482). 
La visibilidad, identificación y denuncia de las categorías que han generado y generan desigualdades y discriminación hacia las mujeres ha sido uno de los logros del desarrollo de la Teoría Feminista.

La tarea de esta perspectiva ético-política, en palabras de Evans (1995), es intentar describir la subordinación de las mujeres, analizar su naturaleza y develar mediante qué mecanismos las mujeres continúan ocupando lugares subalternos. De forma coincidente, Bender (1988) agrega que el feminismo estudia "la opresión de las mujeres en orden de comprender qué es, cómo sucede, la sutil forma en que opera y cómo la opresión, explotación y exclusión afecta diferentes aspectos de nuestras vidas y pensamiento" (p.4) y sostiene que el movimiento está "política, metodológica y filosóficamente comprometido con una transformación social" (p.4).

En suma, el objetivo del feminismo es la superación de la opresión hacia las mujeres y la voluntad de explicar las relaciones sociales entre los géneros.

Por su parte, la teoría jurídica feminista surge en palabras de Kohen (2000) "como un esfuerzo por introducir la teoría feminista en el discurso del derecho (...) planteándose cuestiones críticas de la relación de la vida de las mujeres con el derecho y las instituciones legales" (p.76).

Desde los años ‘60 a la actualidad las diferentes corrientes feministas han concentrado sus esfuerzos en demostrar que el derecho como disciplina discursiva no es neutral, que sus sesgos y valores convalidan una perspectiva patriarcal y desigual respecto a la visión de los hombres y las mujeres. De acuerdo con esto, Bender (1988) explica que:

"Los hombres han tenido el poder de nombrar nuestro mundo y darle sentido a nuestras palabras. Al nombrar se controla cómo agrupamos las cosas, que partes de las cosas son notadas y cuáles ignoradas, y la perspectiva desde la que son entendidas. También aprendemos que esas "cosas" que son nombradas de alguna manera cuentan y que esas cosas sin nombres no merecen nuestra atención" (p.16). 
Esta capacidad nomencladora ha sido también advertida oportunamente por Bourdieu (2000) quien señaló que la verdadera disputa de poder radica en quien dice lo que el derecho es. El problema evidente es que al quedar para los hombres la capacidad de nombrar, su visión e ideología ha impregnado las normas y la interpretación que se realiza de éstas.

El desarrollo de las ideas feministas encontró un interlocutor en la Crítica Jurídica cuyo correlato anglosajón han sido los Critical Legal Studies que emergieron en los '70 en los Estados Unidos. Esta perspectiva señaló la importancia de dar cuenta de la ideología del derecho, las representaciones sociales y las relaciones de poder.

Como señala Cárcova (2000), entre los autores de esta corriente ha "predominado una concepción "deconstructivista" no sólo por la influencia del pensamiento derridiano, sino también por el declarado propósito de exhibir los límites ideológicos del derecho aplicado, su generalizado modo de operar como mecanismo de reproducción del poder y de la dominación social" (p. 8).

Ese marco teórico que nació con la finalidad de poner el foco en la construcción de una sociedad más decente, equitativa y solidaria -menos determinada por jerarquías de clase, status, mérito, raza, género- más descentralizada, democrática, y participativa (Gordon, 2009) - ha centrado su propuesta en la cuestión del discurso jurídico como construcción de sentidos.

Los estudios críticos han realizado enormes esfuerzos por demostrar que el discurso se ha ido retroalimentando del conservadurismo y la necesidad de mantener el statu quo. Así lo expresa Gordon (2009) al decir que:

“(...) el discurso jurídico corriente - los debates legislativos, las discusiones de los abogados con sus clientes, los comentarios y trabajos académicos, etc.- contribuyen como un todo a cimentar este sentimiento, desalentador y complaciente a la vez, de que las cosas deben ser como son y que los cambios mayores no harían más que empeorarlas. El discurso jurídico logra esto de muchas maneras" (p.522). 
Esta capacidad de crear realidades que tiene el lenguaje y de mantener el orden de las cosas se evidencia también en la retórica de la responsabilidad que desentraña interesantemente Balkin (2005). El autor afirma que:

"La responsabilidad y la ideología están también conectadas entre si por nuestras actitudes respecto de los derechos. Cuanto más importante consideremos una actividad o derecho -por ejemplo, la libre expresión o la libertad de contratar-y por ende, cuanto más valiosa consideremos su protección, adoptaremos una tendencia más fuerte a restar importancia a la responsabilidad de los demandados que ejercen tal derecho por los daños que su actividad pudiera causar a otros". (p.144).

$\mathrm{Y}$ advierte que para entender la ideología es menester estudiar los tipos retóricos utilizados cuando se consideran las distintas categorías de derechos en cuestión, cómo pensamos y cómo nos representamos el mundo (p.145).

De igual forma es posible trazar -y lo intentaremos aquíun paralelismo entre el lenguaje de la responsabilidad y la crítica feminista hacia la forma en que se construye el derecho como disciplina. Esa intención encuentra su inspiración en las palabras de Olsen (2009), quien argumenta que:

"Los hombres han oprimido y explotado a las mujeres en el "mundo real"; pero también han colocado a las mujeres en un pedestal, situándolas en un mundo de fantasía. Los hombres exaltan y degradan simultáneamente a las mujeres, como también exaltan y degradan simultáneamente los conceptos del lado "femenino" de los dualismos" (pp. 482-483).

Por consiguiente, esa forma de concebir las relaciones de subordinación por la que ciertos comportamientos son ensalzados, y se estereotipan los rasgos femeninos, ha sido traducida en una doble vara cuyo impacto es claramente reconocible en el discurso judicial (Harari y Pastorino, 2000:123). 


\section{La representación de las mujeres en el discurso de la responsabilidad}

El discurso jurídico construye una ficción idealizada sobre las relaciones sociales partiendo de la premisa de que éstas se edifican desde el consentimiento de los individuos mediante sus decisiones tomadas de manera racional y libre (Gordon, 2009: 154). En ese campo de batalla donde se disputa el sentido y alcance del derecho ha habido ciertas victorias por parte del movimiento feminista en los últimos años. A pesar de ello, algunos sectores de la justicia siguen reproduciendo un discurso misógino y disciplinador. Esto es advertido en el estudio realizado hace un tiempo por Harari y Pastorino (2000) quienes indicaban ya en aquel entonces que:

“(...) a pesar de los cambios recientes en la organización social y legislativa, que han modificado por fuerza la exclusividad del control del mundo público por parte de los varones, la Justicia sigue asignando funciones de género "naturales" a la hora de resolver conflictos individuales y racionalizando la continuidad del statu quo" (p.145).

Para respaldar este argumento recurriremos a la ejemplificación con textos de doctrina que reafirman los estereotipos respecto al rol de la mujer y evidencian los prejuicios de sus autores. Vale aclarar que los textos escogidos son utilizados a modo de ilustrar el sexismo existente en el campo jurídico pero que no procuran componer un relevamiento exhaustivo ni absoluto, por el contrario, constituyen solo una muestra intencional.

Desde este punto de partida tomaremos el discurso de la responsabilidad por daño estético en el que se defiende la idea de que la belleza y la estética son valores eminentemente femeninos. De acuerdo con esto, Iribarne (1995) en el conocido libro "De los daños a la persona", expone que las lesiones estéticas son resarcibles pero que se presentan ciertas dificultades a la hora de cuantificar la condena para quien lo genere.

Entre los elementos a tener en cuenta - explica el autor- se debe ponderar, por ejemplo, el sexo y la edad de la víctima 
y menciona otro problema conexo a esta temática: la pérdida de chance matrimonial (p.568). Se repite la preocupación en torno a la imposibilidad que tendrá la mujer de casarse y se confirma la idea que el matrimonio es, para este doctrinario, una meta que toda representante femenina persigue. Esta idea aún persiste en muchos estratos de la sociedad.

Iribarne recurre a citas para apoyar sus afirmaciones. Por ejemplo, menciona en una de ellas a Quintano Ripollés, quien se preocupaba por la distinción entre el daño físico en el rostro o en partes del cuerpo aún "tutelable por vestiduras". El jurista español explicaba que "(...) no deja de ser abusivo reducir el campo eficiente de la visión al que pudiéramos llamar "público", quedando al margen del tipo de desperfectos en la estética corporal no específicamente facial: piénsese por ejemplo en el tajo producido en un seno femenino" (p.571). Se evidencia así una constante fijación por la belleza y el eventual deterioro del cuerpo de la mujer.

En otra línea, el civilista argentino agrega a su reflexión que "obviamente será mayor el menoscabo inferido a la mujer joven soltera que a la anciana ya abuela. Pero ésta última también lo padece sin duda alguna y debe ser justamente resarcida. En cuanto al sexo, en principio, es indudable la mayor gravedad de la lesión inferida a la mujer" (Iribarne 1995: 572). Y argumenta que no sólo es importante la edad y el sexo de la mujer y, al parecer, su estado civil, sino que también debe considerarse la localización de la lesión. Así, entiende que "las piernas femeninas, por ejemplo, tienen alto valor estético, reconocido desde siempre en nuestra cultura" (p.573).

A los fines de evitar una interpretación maliciosa y que no creamos que su visión está dotada de una fuerte cosificación de la mujer como objeto de belleza cuyo valor esencial es ese, aclara Iribarne que "(..) la armonía, las facciones y la belleza de la integridad corporal no son patrimonio exclusivo de las mujeres, ni siquiera sólo de las mujeres bermosas" (p.573). Afortunadamente para el autor, el derecho las protege y vela por todas ellas sin efectuar a priori valoraciones estéticas. 
Todas estas reflexiones no hacen más que confirmar lo que en su artículo dicen Harari y Pastorino (2000):

"La consideración del aspecto físico femenino como dato relevante es propia de la sociedad en general. Según esta concepción, la mujer cuanto más bonita y joven sea, más posibilidades tendrá de obtener un puesto de trabajo o un marido. Basta con revisar la columna de avisos clasificados de cualquier diario para comprobar que la "buena presencia" de la mujer es una condición sine qua non para acceder a un empleo (...)" (p.138).

Por otro lado, el profesor argentino en su manual defiende una concepción funcional del resarcimiento del daño moral porque entiende que una afectación a las facciones de una mujer que sea notoria y evidente afecta las operaciones o rutinas naturales en orden a "la seducción y la coquetería" (p.577), entonces, la indemnización para él "debería estar ordenada a restablecerlas, proporcionando recursos. Por ejemplo, para el uso generoso de perfumes y cosméticos, o para poseer y mantener un cuidado guardarropas" (p.577).

Este tipo de análisis tiende a reafirmar estereotipos y criterios que son esencialmente falaces porque, como expresa Olsen (2009) "los hombres no son más racionales, objetivos y universales que las mujeres, ni es particularmente admirable ser racional, objetivo y universal, al menos en los términos en que la ideología dominante masculina ha definido esas ideas" (p.488). La belleza, el cuidado estético, la apreciación del cuerpo y la importancia por la icmagen, que parecerían ser valores frívolos o impropios de un ser racional y objetivo, no es un valor eminentemente femenino. Algo así intenta decir Zavala de González (1990) al señalar que "La integridad y normalidad corporales son bienes deseables para cualquier persona, y su pérdida o perturbación son resarcibles con prescindencia del sexo, edad, profesión y estado civil" (p.143).

Más allá de lo cuestionable de su concepto de normalidad corporal, lo rescatable de su reflexión es lo que ha sido 
considerado por diversos precedentes jurisprudenciales cuyo resumen se puede ver representado en el siguiente párrafo de la autora:

"Los valores estéticos no son únicamente referibles a la hipótesis clásica de la "mujer joven, soltera y de agradable aspecto". A las personas de cierta edad y a las del sexo masculino, que desenvuelven su vida en el mundo y no de espaldas a él, no les es indiferente su presentación corporal" (p.145).

Otra polémica se abre respecto al concepto de la disminución de chance matrimonial dado que se consideraba que las señoritas tenían el mandato de casarse. Orgaz -citado por Zavala de González- considera que la pérdida de chance matrimonial no debiera tener distinción entre el hombre y la mujer (p.146). Claramente.

Hasta aquí se pone en evidencia que los doctrinarios y los jueces no han sido -ni son ahora- sujetos ajenos al contexto histórico, su entorno social y sus propias convicciones. Estos elementos se ven plasmados a la hora de resolver un caso y dictar una sentencia (Harari y Pastorino, 2000: 124).

Se ha construido también en el derecho la representación que las mujeres tienen un papel preponderante en la crianza y educación de los hijos y que su misión es la de ser madres de familia. Para referirnos a este prejuicio hemos analizado algunos discursos concernientes a la indemnización por muerte del ama de casa. En la mayoría de ellos se ha sostenido que la mujer cumple tareas de la casa y que esa actividad debe ser reconocida por los esfuerzos que conlleva. Presentan también ciertas afirmaciones discriminatorias que permean en el imaginario colectivo. A modo de ejemplificación de ello, la mencionada Zavala de González (1990) no duda en "reconocer que la trascendencia de la actividad del ama de casa y madre de familia alcanza su punto máximo en los núcleos bumildes, imposibilitados económicamente para sustituir el esencial aporte de aquella" (p.363). 
El valor del trabajo de la mujer y ama de casa presentaría para los defensores de esta perspectiva un doble valor: material y espiritual (Zavala de González, 1992: 363). Numerosos antecedentes jurisprudenciales han sostenido esta idea. En diversos fallos del fuero civil se han realizado afirmaciones como las que a continuación transcribimos:

a) "La economía de los hogares argentinos descansa en gran medida en la eficacia con que el núcleo familiar aparece sostenido por el trabajo, dedicación y administración de la dueña de casa, centrándose en ella todas las posibilidades de aborro (...) por ello la disminución de la capacidad física de la misma debe ser indemnizada"2

b) “(...) es la propia sociedad la que en su evolución y replanteo de las ideas tradicionales ha reconocido beneficios previsionales a las amas de casa como verdaderos agentes que reportan servicios a la comunidad"3

c) "(...) la mujer no es dentro del hogar una figura decorativa y de pura representación, porque ella juega en la sociedad conyugal el papel de socio industrial”

$\mathrm{Y}$ finalmente se aseveró en un fallo de primera instancia que se debe reconocer que el trabajo de las amas de casa tiene un "inconmensurable valor espiritual", no siendo del todo claro el sentido metafísico que los magistrados le pretendieron dar a esas labores.

Se confirma también la idea de la mujer confinada a la vida privada y al hogar. En el modelo de vida familiar se atribuyen roles de género diferenciados entre hombres y mujeres donde estas deben cuidar a los hijos y limpiar la casa (Harari y Pastorino, 2000:139).

2 CNCiv, Sala A, 2/6/1976, JA, 1977-II-252; RepLL, t. XXXVII, p.454, S-615.

3 CNCiv, Sala A, 19/5/1975, LL, 1976-A-139.

4 Cám $1^{\circ}$ Civ.y Com. La Plata, Sala 3², 27/10/1983. Ed. 107-466.

5 Fallo de Primera Instancia, confirmado por la Cámara de Apelaciones en lo Civil y Comercial de Morón, Sala 1ra, 23/12/1982. Ed, 103.309. 
En otra línea argumental, especial mención merece el caso de indemnización por muerte de la madre que es analizado por Garrido (1984) en relación a un fallo de la Cámara de Apelaciones de Morón ${ }^{6}$ del año 1982 donde se ventilaron polémicos argumentos para valorizar labor de la mujer en la casa y agradecer que debido a que ella se encargaba de los quehaceres domésticos, el esposo y los demás miembros de la familia (probablemente hombres), podían realizar otras actividades rentables.

En el texto se utilizan citas del Papa Juan Pablo II para reivindicar la necesidad de revalorizar las "funciones maternas" y se concluye que "el esposo y los hijos sufren un daño material por la muerte de la esposa y de la madre, que atendía con sus cuidados a las necesidades del hogar y hacía de este modo posible el trabajo fuera de la casa o en otros menesteres de los demás miembros de la familia" (p.391). Asimismo, efectúa una antojadiza interpretación del contexto y voluntad de los ciudadanos y dirigentes de la época al referirse a la "(...) preocupación común de las personas y gobernantes a quienes interesa la restauración de la familia y el reconocimiento de su valor como punto de partida del bien común de la sociedad política" (p.399).

Este análisis del discurso de la responsabilidad se vuelve aún más inquietante cuando nos adentramos en aspectos más sensibles como el delito de violación. Como muestra de este trabajo tomamos el aún utilizado manual de derecho penal de Soler (1992). En él, el autor procura explicar el criterio de violencia que debe caracterizar el acto y se encarga de describir los alcances del "uso de fuerza o intimidación" del artículo 119 del Código Penal. Así señala que:

"No debe confundirse la verdadera violencia -que generalmente dejará en las ropas y el cuerpo de la víctima otras señales que las del acto sexual mismo- con la

${ }^{6}$ C. Apel. Civ. Com. Morón, Sala 1ª, 23/12/82, El Derecho, pp. 108-389. 
discreta energía con que el varón vence el pudor de la doncella que, en realidad, desea y consiente. La vis grata puellis (Ovidio) suele darse como criterio separativo entre la violación y el consentimiento" (p.283).

Así expresado, a la luz del concepto de la "vis grata puellis", la mujer que ejerce una negativa que es tomada como un juego de seducción por el hombre, es un criterio de distinción respecto a la víctima que es atacada sexualmente. Este delirio se reafirma con la nota al pie en la que Soler cita a modo de refuerzo conceptual una expresión criolla que dice " $Y$ si quería, mozo, ¿por qué no me volteó?". No hay mucho más que agregar.

El valor lejos está de ser puesto en la autonomía de la mujer para decidir sobre su cuerpo, sino que se pone el ojo en cuestiones absolutamente secundarias como si ella lo sedujo o si se oponía sutilmente. Se reproducen estereotipos machistas como los escandalosos dichos populares "Cuando una mujer dice que no, es que sî" o "se hace la dificil" para justificar el ultraje a su cuerpo e integridad.

Pero las cosas no terminan ahí. Soler sigue profundizando su interpretación del tipo penal señalando que:

"No existe violación cuando media órbita conyugal; pero por lo mismo, el matrimonio no excluye la posibilidad de violación ya que ésta puede producirse por actos contra natura, que no son debidos. Pude también haber oposición legítimamente fundada en la necesidad de evitar el contagio de un mal". (p.285).

La manera en que es caracterizado un acto como la violación acarrea implícitamente esa voluntad totalizadora de racionalizar u ordenar las conductas humanas e ignora la auténtica relación entre la voluntad, el consentimiento, la sexualidad y el cuerpo de las mujeres.

Ellas son presentadas como presas débiles de los hombres -cuando no están casadas, porque entonces parece que para Soler esa condición exime de reproche al acceso carnal forzadoy no como individuos autónomos racionales capaces de tomar 
sus propias decisiones. Este argumento puede ser profundizado mediante la afirmación de Gordon (2009) quien dice que:

"Estos discursos de racionalidad técnica y legal - de "derechos", "consentimiento", "necesidad", "eficacia" y "limitaciones trágicas"- son por supuesto discursos de poder, sólo por la obvia razón de que los mandatos de la ley están respaldados por la fuerza y sus operaciones pueden infligir un dolor enorme".

Muchos de los conceptos del derecho de la responsabilidad, el derecho comercial o el derecho de familia se han originado y consolidado desde la perspectiva única del hombre. Bender (1988) realiza una interesante reflexión acerca del concepto de prudencia y cuidado que se representa en la idea de "hombre razonable" que ha sido concebido por mucho tiempo como un concepto universal para regir la conducta. Señala la autora que:

"Se creía originalmente que el "bombre razonable" era un estándar de género neutral. "Hombre" era usado en el sentido genérico para referirse a la persona o conducta humana. Pero hombre no es un genérico salvo para otros hombres (...) el estándar del "bombre razonable" fue postulado por hombres que porque eran las únicas personas que escribian y discutían el derecho, la filosofía y la politica de ese tiempo, solo teorizaban sobre ellos mismos. Cuando el estándar fue escrito en las opiniones judiciales, tratados y libros de casos, fue escrito sobre $y$ por los hombre" (p.22).

Casos como este se pueden encontrar en nuestro derecho en la idea del "buen hombre de negocios" que subsiste en el artículo 1483 del Código Civil y Comercial, o la idea del "buen padre de familia". No es suficiente con un cambio de palabras, sino que lo que Bender plantea es que es necesario cambiar el modelo, de lo contrario no servirá. Por ello argumenta que "las distinciones de género a menudo han sido reforzadas por duales atribuciones de razón y racionalidad para los hombres y emoción e intuición para las mujeres" (p.23). Sustituir la idea de hombre razonable por persona razonable no evita la 
reproducción del vicio de fondo que es el criterio de razón y racionalidad subyacente (Bender 1988:23).

\section{Conclusiones}

A lo largo de este trabajo hemos intentado recapacitar acerca de los prejuicios machistas que subyacen tanto en el discurso del derecho privado como en el derecho penal. El espíritu de abordar la problemática aquí desarrollada está lejos de pretender una apropiación de las temáticas feministas, sino que procura ser un aporte en el actual contexto donde muchos actores de la sociedad comienzan a pensar seriamente en la deconstrucción de sus ideas y representaciones sobre la mujer.

Vivimos tiempos de mucho cambio. Esta es una buena oportunidad para pensar la génesis del derecho e intentar transformarlo. Como señalaba Bender (1988):

"Todas nuestras normas y estándares han sido masculinos. Si extraemos los sesgos masculinos de nuestro lenguaje, métodos y estructuras, no tendremos nada -no habrá palabras, no habrá conceptos, no habrá ciencia, no habrá métodos, no habrá derecho. Los sesgos conviven con los conceptos alrededor de los que hemos estructurado nuestro sistema politico y social" (19).

Los años que han sido necesarios para alcanzar el empoderamiento de las mujeres no hacen más que demostrar la complejidad de este fenómeno. Todavía queda mucho camino por transitar en la búsqueda de la igualdad real.

Finalmente es importante marcar que, pese a que los trabajos utilizados como fuentes bibliográficas en este artículo datan de algunos años, no han perdido vigencia y utilidad. Lo valioso es comprender que a veces son los problemas los que pueden ser viejos por persistentes (en tanto no han encontrado solución), pueden ser viejos por recurrentes o pueden ser nuevos cuando son producto de un inédito desafío que no existía en el pasado (Garzón Valdés, 2008). En este caso en particular, la persistente discriminación sexista, el recurrente lenguaje machista y la 
emergente ola feminista, hace que los problemas desarrollados previamente tengan en simultáneo todas esas características y por lo tanto se justifique seguir teorizando acerca de ellos.

\section{Bibliografía}

BALKIN, Jack M (2005). La Retórica de la Responsabilidad. En La Responsabilidad Extracontractual, Carlos F. Rosenkrantz (Comp.) (123-146). Buenos Aires: Gedisa.

BENDER, Leslie (1988). A Lawyer's Primer on Feminist Theory and Tort. 38 J. Legal Educ. (3-37).

BOURDIEU, Pierre y TEUBNER Gunther (2000). La fuerza del derecho. España: Siglo del Hombre Editores.

CAPELLA, Juan Ramón (2008). La Fruta Prohibida. Madrid: Trotta (134).

CARCOVA, Carlos María (2000). Notas acerca de la Teoría Crítica del Derecho. Buenos Aires. Recuperado de: https://goo.gl/ XeoCvk.

DE SOUSA SANTOS, Boaventura. (2006). De la Mano de Alicia. Lo Social y lo Político en la Posmodernidad. Bogotá: Nuevo Pensamiento Jurídico. (35).

EVANS, Judith (1995) , Feminist theory today. Sage publications: London.

GARRIDO, Roque Fortunato (1984). La indemnización por muerte de la madre y un criterio objetivo: el costo de la madre sustituta.

GARZÓN VALDÉS, Ernesto (2008). 30 minutos de Filosofía del Derecho. Viejos nuevos problemas. ISONOMIA No 28 .

GORDON, Robert W (2009). Cómo 'descongelar' la realidad legal: una aproximación crítica al derecho. En Desde Otra Mirada. Textos de Teoría Crítica del Derecho, Christian Courtis (Comp.). Eudeba. (521 y ss).

HARARI Sofía y PASTORINO Gabriela L. Acerca del Género y el Derecho, en El Derecho en el Género y el Género en el Derecho, Haydée Birgin (Comp.) Biblos (121-147).

IRIBARNE, Héctor P. (1993). De los Daños a la Persona. Ediar (567-578). 
KOHEN, Beatriz (2000). El feminismo jurídico en los países anglosajones: el debate acutal. En Birgin, H, compiladora. El derecho en el género y el género en el derecho. Editorial Biblos, Colección Identidad, Mujer y Derecho: Buenos Aires (73-106). OLSEN, Frances (2009). El Sexo del Derecho. En Desde Otra Mirada. Textos de Teoría Crítica del Derecho, Christian Courtis (Comp.), Eudeba ( 481 y ss).

SOLER, Sebastián. Tratado de Derecho Penal. Tea, T. III, (281-291). ZAVALA DE GONZÁLEZ, Matilde (1990), Resarcimiento de Daños. Hammurabi, T. 2a, (137-150 y 361-369). 